V. M. Bondarenko ${ }^{1}$, Yu. M. Orlovskaja ${ }^{2}$, M. V. Styopochkina ${ }^{3}$

\title{
ON HASSE DIAGRAMS CONNECTED WITH THE 1-OVERSUPERCRITICAL POSET $(1,3,5)$
}

We study combinatorial properties of Hasse diagrams of posets minimax equivalent to the smallest oversupercritical poset with trivial group of automorphisms.

Introduction. M. M. K leiner [6] proved that a poset S has finite representation type if and only if it does not contain the subsets of the form $(1,1,1,1),(2,2,2),(1,3,3),(1,2,5)$ and $(1,4)$, which are called the critical posets. By $(P, Q)$ is denoted the poset which is the direct sum of $P$ and $Q ;$ by $\left(i_{1}, i_{2}, \ldots, i_{p}\right)$ is denoted the poset wich is the direct sum of chains of length $i_{1}, i_{2}, \ldots, i_{p}$. In [2] it is proved that a poset is critical with respect to the positivity of the Tits quadratic form if and only if it is minimax equivalent to a critical poset (the notion of minimax equivalence was introduced in [1]); in [2] all such posets was completely described.

A similar situation occurs for the tame posets. L. A. Nazarova [7] proved that a poset $S$ is tame if and only if it does not contain subsets of the form $(1,1,1,1,1),(1,1,1,2),(2,2,3),(1,3,4),(1,2,6)$ and $(4,5)$; these sets are called supercritical. In [3] it is proved that a poset is critical with respect to the nonnegativity of the Tits form if and only if it is minimax equivalent to a supercritical poset; all such critical posets was described in [4].

The posets that are differ from the supercritical sets in the way as the supercritical sets differ from critical posets are called 1-supersupcritical. More precisely (see [5]), it is the following posets: 1) $(1,1,1,1,1,1), 2)(1,1,1,1,2)$, 3) $(1,1,2,2)$, 4) $(1,1,1,3)$, 5) $(2,3,3), 6)(2,2,4)$, 7) $(1,4,4)$, 8) $(1,3,5), 9)(1,2,7)$, 10) $(6$, И).

We study combinatorial properties of the posets which are minimax equalently to the smallest 1-oversupercritical poset with trivial group of automorphisms,i. e. the poset $(1,3,5)$.

Formulation of the main theorems. Let $\mathrm{S}$ be a finite poset. The Hasse diagram of $S$ is by definition the directed graph $H(S)$ with the vertices $x \in S$ and the arrows $(x, y), x, y \in S$, where $y$ covers $x$ (i. e. $x<y$ and there is no $z$ satisfying $x<z<y$ ). We call the 0-length of an oriented path of $H(S)$ the number of its vertices, and denote by $I_{\min }(\mathrm{S})$ (respectively, $I_{\max }(\mathrm{S})$ ) the 0-length of a most short (respectively, long) oriented path of $H(S)$. We denote by [S] the set of all posets minimax equivalent to $S$ (see [1]) and put

$$
\mathrm{L}_{\min }(\mathrm{S})=\min _{\mathrm{X} \in[\mathrm{S}] \sim} I_{\min }(\mathrm{X}), \quad \mathrm{L}_{\max }(\mathrm{S})=\max _{\mathrm{X} \in[\mathrm{S}] \sim} I_{\max }(\mathrm{X}) \text {. }
$$

Theorem 1. For $S=(1,3,5), L_{\min }(S)=1, L_{\max }(S)=8$.

Theorem 2. Let $X \in[(1,3,5)] \sim$. Then $1 \leq I_{\min }(X) \leq 6,4 \leq I_{\max }(X) \leq 8$, $n(X) \in\{2,3,4\}$.

Proofs of the theorems. The posets minimax equivalent to $(1,3,5)$ were classified in [5]. They are given (up to isomorphism and anti-isomorphism) by the following table.

ISSN 1810-3022. Прикл. проблеми мех. і. мат. - 2018. - Вип. 16. - С. 30- 32 


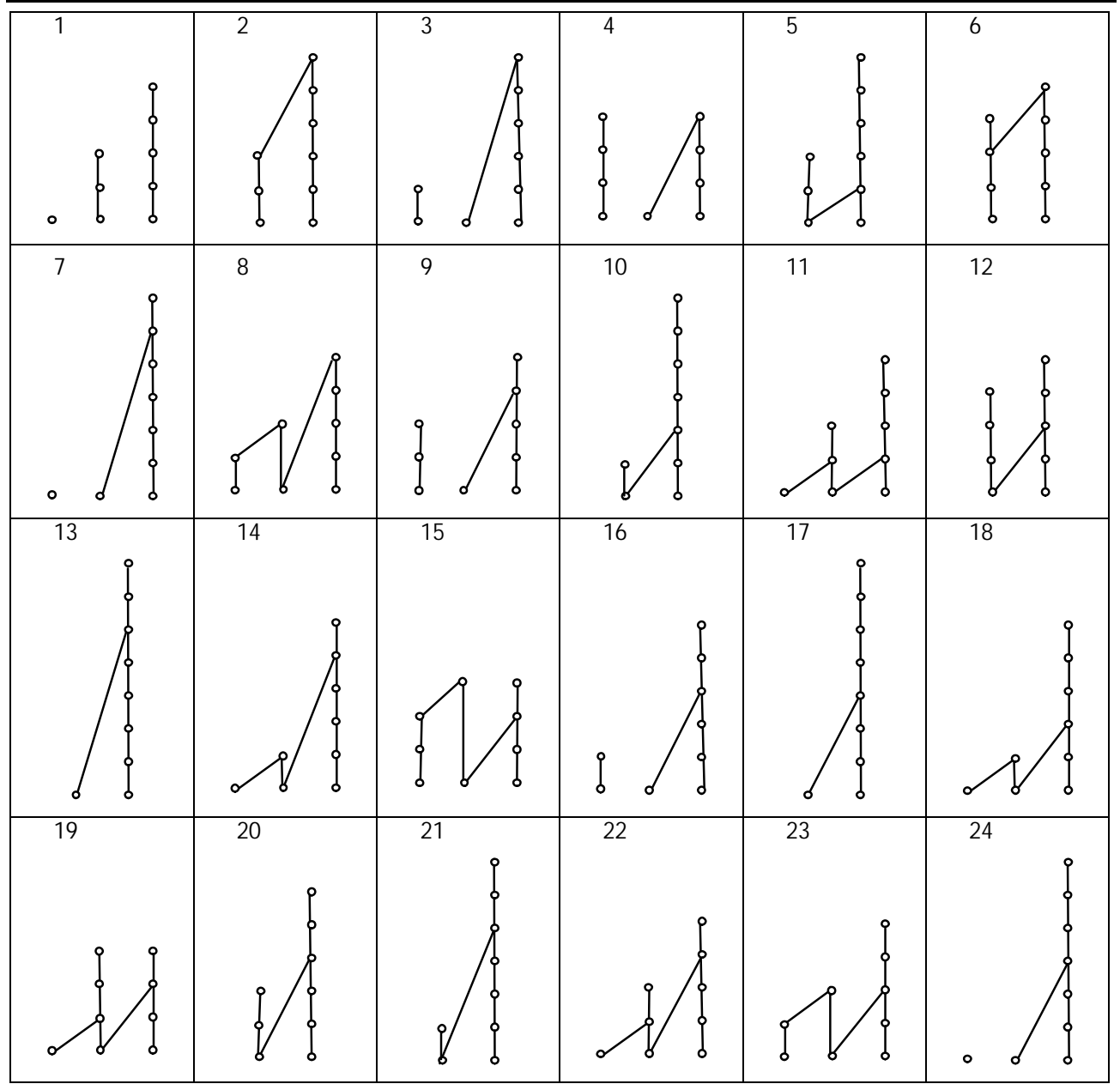

We have the next theorem.

Theorem 3. The following holds for posets 1- 24:

\begin{tabular}{|c|c|c|c|c|c|c|c|c|c|c|c|}
\hline $\mathrm{N}$ & $\mathrm{I}_{\min }$ & $\mathrm{I}_{\max }$ & $\mathrm{n}$ & $\mathrm{N}$ & $\mathrm{I}_{\min }$ & $\mathrm{I}_{\max }$ & $\mathrm{n}$ & $\mathrm{N}$ & $\mathrm{I}_{\min }$ & $\mathrm{I}_{\max }$ & $\mathrm{n}$ \\
\hline 1 & 1 & 5 & 3 & 9 & 3 & 5 & 3 & 17 & 6 & 8 & 2 \\
2 & 4 & 6 & 2 & 10 & 2 & 7 & 3 & 18 & 2 & 6 & 4 \\
3 & 2 & 6 & 3 & 11 & 3 & 5 & 4 & 19 & 3 & 4 & 4 \\
4 & 2 & 4 & 3 & 12 & 4 & 5 & 3 & 20 & 3 & 6 & 3 \\
5 & 3 & 6 & 3 & 13 & 4 & 8 & 2 & 21 & 2 & 7 & 3 \\
6 & 4 & 5 & 3 & 14 & 2 & 6 & 4 & 22 & 3 & 5 & 4 \\
7 & 1 & 7 & 3 & 15 & 2 & 4 & 4 & 23 & 2 & 5 & 4 \\
8 & 2 & 5 & 4 & 16 & 2 & 6 & 3 & 24 & 1 & 7 & 3 \\
\hline
\end{tabular}

Here the numbers $I_{\min }, I_{\max }$ and $\$$ denote, respectively, $I_{\min }\left(S_{i}\right)$, $I_{\max }\left(S_{i}\right)$ and $n\left(S_{i}\right)$ for $i=N$, where $N$ runs from 1 to 24 and $S_{i}$ is the $i$ th poset in the table.

The proof is carried out by direct calculations.

Theorems 1 and 2 follow from Theorem 3. 
1. Bondarenko V. M. On (min, max)-equivalence of posets and applications to the Tits forms // Bull of the University of Kiev (series: Physics \& Mathematics). - 2005. - № 1. - P. 24- 25.

2. Bondarenko V. M., Stepochkina M. V. (Min, max)-equivalence of partially ordered sets and the Tits quadratic form // Zb. Pr. Inst. Mat. NAN Ukr/ Problems of Analysis and Algebra / . - 2005. - 2,№ 3. - P. 18- 58 (in Russian).

3. Bondarenko V. M.,Stepochkina M. V. (Min-, max)-equivalency of posets and nonnegative Tits forms // Ukrainian Math. J . - 2008. - 60,№ 9. - P. 1349- 1359.

4. Bondarenko V. M.,Stepochkina M. V. Description of posets critical with respect to the nonnegativity of the quadratic Tits form // Ukrainian Math. J. - 2009. 61,№ 5. - P. 734- 746 .

5. Bondarenko V. V., Bondarenko V. M., Stepochkina M. V., Chervyakov I. V. 1-oversupercritical partially ordered sets with trivial group of automorphisms and minequivalence. I. // Nauk. Visn. Uzhgorod. Univ., Ser. Mat. - 2011. - 22, № 2. P. 17- 25 (in Russian).

6. Kleiner M. M. Partially ordered sets of finite type // Zap. Nauch. Semin. LOMI. - 1972. - 28. - P. 32- 41 (in Russian).

7. Nazarova L. A. Partially ordered sets of infinite type // Izv. Akad. Nauk SSSR Ser. Mat. - 1975. - 39,№ 5. - P. 963-991 (in Russian).

ПРО ДІАГРАМИ ХАССЕ, ПОВ'ЯЗАНІ 3 1-НАДСУПЕРКРИТИЧНОЮ ЧАСТКОВО ВПОРЯДКОВАНОЮ МНОЖИНОЮ $(1,3,5)$

Вивчали комбінаторні властивості діаграм Хассе частково впорядкованих множин, мінімаксно еквівалентних найленшій надсуперкритичній частково впорядкованій множині з тривіальною групою автоморфізмів.

\section{О ДИАГРАММАХ ХАССЕ, СВЯЗАННЫХ С 1-НАДСУПЕРКРИТИЧЕСКИМ ЧАСТИЧНО УПОРЯДОЧЕННЫМ МНОЖЕСТВОМ $(1,3,5)$}

Изучали комбинаторные свойства диаграмл Хассе частично упорядоченных множеств, минимаксно эквивалентных наименъшему надсуперкритическому частично упорядоченному множеству с тривиальной группой автоморфизмов.

1Institute of Mathematics of NAN of Ukraine, Kyiv

${ }^{2} \mathrm{~K}$ oroliov Military Institute of Zhytomyr,Zhytomyr

3Zhytomyr National University of Agriculture and

Obtained

Ecology,Zhytomyr 